\title{
Relationship between Nurses' Competencies and Quality of Patient Care at Intensive Care Units
}

\author{
Mona A. Osman', Manal M. Ibrahim², and Gehan M. Diab ${ }^{3}$ \\ ${ }^{1}$ B.Sc. Nursing Science, ${ }^{2}$ Professor of Nursing Administration, ${ }^{3}$ Assistant Professor of Nursing \\ Administration
}

\begin{abstract}
Background: Competent, good and safe intensive and critical care nursing is based on the knowledge, attitudes and values, experiences and skills of the ICU nurses. So, employing interested and competent nurses and considering the standards required in the ICU can increase the quality of care. The purpose of the study: Investigate the relationship between nurses' competencies and quality of patient care provided at intensive care units. Study design: A descriptive co-relational design was used to carry out this study. Study setting: The study was conducted in the intensive and intermediate care units at Menoufia University Hospitals. Study sample: A convenient sample of 145 staff nurses and 145 critically ill patients, taken care of by the studied nurses. Data collection instruments: The first instrument was a modified version of the Intensive and Critical Care Nursing Competence Scale. The second instrument was the patient's care quality observation checklist. Results: The present study showed that more than half of the studied nurses $(54.5 \%)$ had good level of competency and it was associated with good total knowledge level (88.2\%), positive attitudes $(97.2 \%)$ and satisfactory level of practice $(95.9 \%)$. The study results illustrated that the majority of the studied patients $(61.4 \%)$ had moderate level of quality of patient care. There was no statistical correlation between socio-demographic characteristics of the studied nurses and total competency level and also those of the studied patients and total quality of care level ( $p>0.01)$. Conclusion: There was a highly statistical significant positive correlation between the competency of nurses and the quality of patient care at Intensive Care Units. Recommendations: Competence should be assessed regularly in clinical practice to explore individual learning needs for continuing education to improve the quality of health care.
\end{abstract}

Keywords: Competencies - Critical Care Nursing - Intensive care units - Quality of Patient Care.

\section{Introduction:}

Medical advances and new technologies have been more likely to increase hospital nurse staffing requirements than to decrease them (Buchan, O'May and Dussault, 2013). The growing use of intensive care beds is one example, where professional nurse staffing is the highest. In nursing practice, nurses get to demonstrate on a regular basis clinical competence as well as a sound theoretical knowledge base according to nationally recognized frameworks (European Federation of Critical Care Nursing Association. EFCCNa, 2013). The nursing profession has suffered from important changes in response to the needs of citizens' health and to improve the quality of the health service in the country. At the basis of this development there is an increase of the nurses' knowledge, competencies and responsibilities (Alfieri, Mori, Barbui and Sarli, 2017).
Critical care units should deliver care using only appropriately trained and experienced registered Nursing staff (British Association of Critical Care Nurses. BACCN, 2010). As, critical care nursing is

an own nursing specialty (Lakanmaa, Suominen, Perttil“a, Puukka, and Leino-Kilpi, 2012) that provides support for patients requiring complex medical and nursing interventions for life threatening conditions and injuries, these comprehensive interventions should be delivered and closely monitored by specially-trained multidisciplinary health care professionals of whom highly trained nurses constitute a significant component (Welsh Government, 2013). All of those nurses who are appointed to critical care should be allocated a period of supernumerary practice (Faculty of Intensive 


\section{Relationship between Nurses' Competencies and Quality of Patient Care at Intensive Care \\ Units}

Care Medicine and the Intensive Care Society. FICM and ICS, 2015).

Critical care nurses are a crucial element in the delivery of evidence-based, patient-centered care to patients with complex needs. During a career in critical care, nurses are expected to acquire and maintain specialized knowledge, critical thinking skills and practical expertise, which is considered beyond those traditionally, included in general nurse education (Critical Care Networks National Nurse Leads Group. CC3N, 2012). Additionally, critical care nurses are members of healthcare teams who work closet to the end-of-life patients and their families. Thus, they need to have competency in providing care for particular groups of clients in order to maintain standard of care (Tongprateep, 2015). Factors that can affect the performance of the critical care nurses in caring for terminally ill patients include age, education, lack of training or experience in caring for terminally ill patients (Srisuwan, Matchim and Nilmanat, 2014), lack of overall knowledge in relation to end-of life care, and lack of knowledge regarding managing symptoms, or lack of knowledge and skills in providing psychosocial and spiritual care (Ayed, Sayej, Harazneh, Fashafsheh and Eqtait, 2015).

Competence concept is very multidimensional as it is focusing on clinical practice, ethics, collaboration, leadership, education, and development work and strongly related to age, work experience, and frequency of using specific competencies (Lakanmaa, Suominen, Ritmala-Castrén,Vahlberg and Leino-Kilpi, 2015). Competence is the written statement which refers to the combination of knowledge, skills and attitudes of a person who performs at a predefined level and takes into consideration the broader practice implications and its effects on patients. Competency is defined as tasks undertaken correctly and skillfully (PijlZieber, Barton, Konkin, Owosoga and Caine, 2014). Additionally, competence is defined as: "The combination of skills, knowledge and attitudes, values and technical abilities that underpin safe and effective critical care nursing care and interventions (Critical Care NetworksNational Nurse Leads, CC3N, 2015).

Competent, good and safe intensive and critical care nursing is not only based on the knowledge base and skill base of the ICU nurse; is also based on the attitude and value base, experience base and personal base of the ICU nurse (Lakanmaa, 2012). Critical care nurses play a pivotal role in the assessment, care and recovery of those patients who experience critical illness. Their experience, competence and knowledge allow them to work both on their own and in partnership with wider multidisciplinary healthcare teams (CC3N, 2015).

Health care organizations worldwide are striving to offer high quality patient care (Greenfield, Kellner, Townsend, Wilkinson and Lawrence, 2014). One of the most important topics in the health service is quality of health care. Improving and even maintaining the quality of care is a critical dilemma that healthcare administrators face (Chahal and Kumari, 2012). Nurses are required to provide safe, high quality services for the public, and support improvements in the critical care environment so that the safety and quality of care is continually enhanced (CC3N, 2015). Working in intensive care units (ICUs) and dealing with complex situations requires many mental and physical resources of nurses, who are the only healthcare professionals providing direct patient care at the bedside 24 hours per day, 7 days per week (Gershengorn and Garland, 2016).

With the globalization of health care and the development of collaborative teams to address and sustain effective quality care, nursing knowledge can serve as the foundation to engage other professionals in interprofessionality and link to inter-professional competencies, knowledge and practice (Meleis, 2015). As a result, the effective use of experienced Critical Care nurses can greatly improve patient care, and reduce the incidence of complications for patients (Francis, 2013 Berwick, 2013).

Significance of the study: 


\section{Relationship between Nurses' Competencies and Quality of Patient Care at Intensive Care \\ Units}

The critical care environment is a constantly changing field with emerging technologies and therapies to aid patient recovery through the often life-threatening illness. Nurses need to ensure they develop and maintain competence in practice to meet the challenges presented (CC3N, 2015). On this study, the investigator will spot the light on the relationship between nurses' competencies and quality of patient care provided at intensive care units which provide important information about nurses' skills, knowledge and abilities to help critically ill patients and also degree of patient satisfaction about care provided and patient outcomes.

\section{Purpose of the study:}

This study's purpose was to assess the relationship between nurses' competencies and quality of patient care provided at intensive care units through the following objectives:

Assess the level of competencies of intensive care nurses.

Assess the level of quality of patient care.

Assess the relationship between nurses' competencies and quality of patient care.

\section{Research questions:}

What is the level of nurses' competencies at intensive care units?

What is the level of quality of patient care provided at intensive care units?

What is the relationship between nurses' competencies and quality of patient care provided at intensive care units?

\section{Methods:}

\section{Research Design:}

A descriptive correlational design was used to carry out this study.

Setting:

This study was conducted at Menoufia University Hospital in the following units: Anesthesia intensive care unit which includes three zones - Emergency intensive care units which include five different adult intensive care units - The intermediate care units which include seven different adult intermediate care units.

\section{Sample:}

Two groups of sample were used in the current study. The first group included a convenient sample of 145 nurses working in intensive and intermediate care units and the second group included 145 critically ill patients were chosen as they were taken care of by the staff nurses who agreed to participate in the study regardless of the high flow of patients to the Intensive and Intermediate Care Units.

Instruments:

Data of the present study was collected using two different instruments.

Instrument one: The Intensive and Critical Care Nursing Competence Scale (Version No. 1) that was adapted from Lakanmaa (2012) and modified by the investigator. The scale measures basic competence in intensive and critical care nursing. The modified scale was a 3-point Likert scale and comprises 147 items included in four parts: part one for nurses' social characteristics, part two for the knowledge test (36 items), part three for attitudes questionnaire (10 items) and part four for practice assessment which include the experiences' observation checklist (13 items) and skills' observation checklist (88 items).

The scoring system of Instrument one:

Every item was measured by three points Likert scale (0-1-2). Total range was between score 0-294. For part one, the scores of 2, 1 and 0 were respectively assigned to responses correct \& complete answer, correct but incomplete answer and incorrect answer. For part two, the same scores were assigned to responses: agree, cannot specify and disagree and for part three, they were assigned to responses of done correctly, done but incorrect and not done. All scores will be expressed as percentages. A score that is less than $60 \%$, it indicates poor competence. A score that ranges from $60 \%$ to $<75 \%$, it indicates fair competence. A score that ranges from $75 \%$ to $<85 \%$, it indicates good competence. A score that is $85 \%$ and more, it indicates excellent competence. 


\section{Relationship between Nurses' Competencies and Quality of Patient Care at Intensive Care \\ Units}

Instrument two: An observation checklist to assess the quality of care provided to the patient that was adapted from (Hospital Nursing Services Administration Manual, 1999) and modified by the investigator. It consisted of two parts: part one for the patients' socio-demographic data and part two contained totally 70 items to be assessed if they were always, sometimes or never done and divided into eleven categories which were: hygiene and physical comfort (7 items), activities and body mechanics (7 items), rest and sleep (3 items), safety ( 8 items), nutrition, fluid and electrolyte balance (6 items), elimination (11 items), oxygen and ventilation (6 items), sensory (7 items), meeting emotional needs (6 items), patient and family teaching (4 items) and discharge (5 items).

The scoring system of Instrument two:

Every item was measured with three points Likert scale (0-1-2). The possible response will be always, sometimes or never in which "always" was given 2 points, "sometimes" was given 1 point and "never" was given 0 point. All scores were expressed as percentages. If the score was $75 \%$ and more, it was considered as high level of patient care quality. If the score ranged from $60 \%$ to less than $75 \%$, it was considered as moderate level of patient care quality. If the score was less than $60 \%$, it was considered as low level of patient care quality.

\section{Validity:}

The instruments were distributed to a panel of experts consisted of five assistant professors in the field of nursing administration and were obtained by explaining the purpose, nature, the potential benefits and time of conducting this study, how data will be collected, any needed procedures, expected outcomes and their right to withdraw from the research study at any time in case of violation of their rights.

The respondents were assured that the data was treated as strictly confidential and for the purpose of research only; furthermore, the respondents' anonymity was maintained, as medical-surgical nursing to judge the content and face validity of the instruments, presented from different faculties of nursing affiliated to Menoufia and Tanta universities.

\section{Reliability:}

Cronbach's alpha test was 0.98 for nurses for Intensive and Critical Care Nursing Competence Scale and it was 0.89 for the patient quality of care checklist.

\section{Pilot study:}

Pilot study was conducted before the starting of the actual data collection for both of two instruments to test feasibility, clarity, and applicability of the instruments and detect obstacles that may be encountered during the actual data collection and necessary modifications were carried out. The pilot study was conducted on $10 \%$ of the study participants which number was 22 nurses. Based on the result of the pilot study, there was no modification on the instruments of data collection and the 22 nurses of the pilot study were not excluded from the main study sample.

\section{Ethical consideration:}

Approval of the Faculty of Nursing Ethical Research Committee was obtained. The study was conducted with careful attention to the ethical standards of research and rights of the participants. The respondent's rights were protected by ensuring their voluntary participation. Written informed consents

they were not be required to mention their name.

\section{Procedure}

1. An official letter was sent from the Dean of the Faculty of Nursing, Menoufia University, to the directors of Menoufia University Hospital, in Shibin El-Kom, explaining the purpose and methods of data collection.

2. Data was collected from staff nurses and their patients from the previously- 
mentioned study setting. Data was collected using the self-administered questionnaires; which were filled by the nurses themselves during working hours and filling them needed from 10:15 minutes and the observation checklists; which were filled by the investigator for three times for every nurse and for every patient over different shifts (Morning shift, Evening shift and Night shift). Data collection lasted for 8 months, from January 2019 to August 2019.

\section{Statistical design:}

\section{Results:}

Table (1): Percent distribution of the studied nurses according to their socio-demographic characteristics $(n=145)$ :

\begin{tabular}{|c|c|c|}
\hline \multirow{2}{*}{ Characteristics } & \multicolumn{2}{|c|}{$\begin{array}{l}\text { The studied nurses } \\
(n=145)\end{array}$} \\
\hline & $\mathbf{N}$ & $\%$ \\
\hline $\begin{array}{l}\text { Age (in years) } \\
\text { - }(20-<30) \\
\text { - }(30-<40) \\
\text { - } \geq 40\end{array}$ & $\begin{array}{c}117 \\
26 \\
2\end{array}$ & $\begin{array}{c}\frac{80.7}{17.9} \\
1.4\end{array}$ \\
\hline $\begin{array}{c}\text { Range } \\
\text { Mean } \pm \text { SD }\end{array}$ & \multicolumn{2}{|c|}{$\begin{array}{c}(21-48) \\
26.98 \pm 4.05\end{array}$} \\
\hline $\begin{array}{ll}\text { Experience (in years) } \\
: & <5 \\
: & (5-<10) \\
: & (10-<15) \\
: & \geq 15\end{array}$ & $\begin{array}{c}66 \\
59 \\
16 \\
4\end{array}$ & $\begin{array}{c}\frac{\mathbf{4 5 . 5}}{40.7} \\
11.0 \\
2.8\end{array}$ \\
\hline $\begin{array}{c}\text { Range } \\
\text { Mean } \pm \text { SD }\end{array}$ & \multicolumn{2}{|c|}{$\begin{array}{c}(1.0-20.0) \\
5.531 \pm 3.71\end{array}$} \\
\hline $\begin{array}{l}\text { Department } \\
\text { Intensive care units } \\
\text { Intermediate care units }\end{array}$ & $\begin{array}{r}120 \\
25\end{array}$ & $\frac{\mathbf{8 2 . 8}}{17.2}$ \\
\hline $\begin{array}{l}\text { Educational level } \\
\text { - } \text { Nursing school diploma degree } \\
\text { - } \text { Associated degree in nursing } \\
\text { - } \text { Bachelor degree in nursing } \\
\text { Post graduate degree in nursing }\end{array}$ & $\begin{array}{c}2 \\
108 \\
30 \\
5\end{array}$ & $\begin{array}{c}1.4 \\
\frac{74.5}{20.7} \\
3.4\end{array}$ \\
\hline $\begin{array}{l}\text { Gender } \\
\text { : Male } \\
\text { - } \text { Female }\end{array}$ & $\begin{array}{l}50 \\
95\end{array}$ & $\begin{array}{l}34.5 \\
\mathbf{6 5 . 5}\end{array}$ \\
\hline $\begin{array}{l}\text { Marital status } \\
\text { - Unmarried } \\
\text { - Married }\end{array}$ & $\begin{array}{c}51 \\
94\end{array}$ & $\begin{array}{l}35.2 \\
\mathbf{6 4 . 8}\end{array}$ \\
\hline
\end{tabular}




\section{Relationship between Nurses' Competencies and Quality of Patient Care at Intensive Care \\ Units}

This table illustrated that the highest percent of nurses $(80.7 \%)$ in the study sample were at age ranges from 20 to less than 30 years with mean \pm SD $(26.98 \pm 4.05)$, less than half of the study sample $(45.5 \%)$ has less than 5 years of experience and the mean \pm SD $(5.53 \pm 3.71)$. In addition, the majority of the study sample nurses $(82.2 \%)$ were working at intensive care units, about three quarters of the study sample nurses $(74.5 \%)$ had associated degree in nursing and approximately two thirds of the studied nurses were female and married (65.5\% \& $64.8 \%$ respectively).

Table (2): Percent distribution of the studied nurses according to their total competency level $(n=145)$ :

\begin{tabular}{|c|c|c|}
\hline $\begin{array}{c}\text { Total } \\
\text { competency }\end{array}$ & \multicolumn{2}{|c|}{$\begin{array}{c}\text { The studied nurses } \\
(n=145)\end{array}$} \\
\hline level & $\mathrm{N}$ & $\%$ \\
\hline $\begin{array}{ll}\text { - } & \text { Poor }<60 \\
\text { - } & \text { Fair }(60-<75) \% \\
\text { - } & \text { Good }(75-<85) \% \\
\text { - } & \text { Excellent } \geq 85 \%\end{array}$ & $\begin{array}{c}3 \\
13 \\
79 \\
50\end{array}$ & $\begin{array}{c}2.1 \\
9.0 \\
\mathbf{5 4 . 5} \\
34.5\end{array}$ \\
\hline $\begin{array}{c}\text { Range } \\
\text { Mean } \pm \text { SD }\end{array}$ & \multicolumn{2}{|c|}{$\begin{array}{c}(132-259) \\
226.21 \pm 20.526\end{array}$} \\
\hline
\end{tabular}

This table showed that more than half of the studied nurses $(54.5 \%)$ had good level of competency while the lowest percent of them
$(2.1 \%)$ had poor level of competency with mean \pm SD $(226.21 \pm 20.52)$.

Table (3): Percent distribution of the studied nurses according to their total knowledge level as part of their competencies $(n=145)$ :

\begin{tabular}{|l|c|c|c|}
\hline \multirow{2}{*}{$\begin{array}{c}\text { Total } \\
\text { Knowledge } \\
\text { Level }\end{array}$} & \multicolumn{2}{|c|}{$\begin{array}{c}\text { The studied nurses } \\
(\mathbf{n = 1 4 5})\end{array}$} & \\
\cline { 2 - 4 } & $\mathrm{N}$ & $\%$ & \\
\hline - Poor $<60 \%$ & 3 & 2.1 & \\
- Fair $(60-<75) \%$ & 14 & 9.7 & \\
- Good $\geq 75 \%$ & $\underline{\mathbf{1 2 8}}$ & $\underline{\mathbf{8 8 . 2}}$ & \\
\hline Range & \multicolumn{2}{|c|}{$\mathbf{3 4 - \mathbf { 7 1 }}$} & \\
Mean \pm SD & \multicolumn{2}{|c|}{$\mathbf{5 9 . 2 4} \pm \mathbf{6 . 1 0 0}$} & \\
\hline
\end{tabular}

This table clarified that the total knowledge level of the most percent of the studied nurses $(88.2 \%)$ was good while the least percent of them $(2.1 \%)$ had had poor total knowledge level with mean \pm SD $(59.24 \pm 6.10)$.

Table (4): Percent distribution of the studied nurses according to their total attitude level as a part of their competencies $(n=145)$ : 


\section{Relationship between Nurses' Competencies and Quality of Patient Care at Intensive Care}

Units

\begin{tabular}{|c|c|c|}
\hline \multirow{2}{*}{$\begin{array}{c}\text { Total } \\
\text { Attitude } \\
\text { Level }\end{array}$} & \multicolumn{2}{|c|}{$\begin{array}{c}\text { The studied nurses } \\
(\mathbf{n = 1 4 5 )}\end{array}$} \\
\cline { 2 - 3 } & $\mathbf{N}$ & $\mathbf{\%}$ \\
\hline - Negative $<60 \%$ & 4 & 2.8 \\
- Positive $\geq 60 \%$ & 141 & $\underline{\mathbf{9 7 . 2}}$ \\
\hline Range & \multicolumn{2}{|c|}{$\mathbf{( 0 - 2 0 )}$} \\
Mean \pm SD & \multicolumn{2}{|c|}{$\mathbf{1 8 . 4 0 \pm 3 . 1 3 4}$} \\
\hline
\end{tabular}

This table stated that the most of the studied least of them $(2.8 \%)$ had negative attitudes nurses $(97.2 \%)$ had positive attitudes while the with mean \pm SD $(18.40 \pm 3.13)$.

Table (5): Percent distribution of the studied nurses according to their total practice level as a part of their competencies $(n=145)$ :

\begin{tabular}{|c|c|c|}
\hline \multirow{2}{*}{$\begin{array}{c}\text { Total } \\
\text { practice } \\
\text { level }\end{array}$} & \multicolumn{2}{|c|}{$\begin{array}{c}\text { The studied nurses } \\
(\mathbf{n = 1 4 5})\end{array}$} \\
\cline { 2 - 3 } & $\mathrm{N}$ & $\%$ \\
\hline - Unsatisfactory $<70 \%$ & 6 & 4.1 \\
- Satisfactory $\geq 70 \%$ & 139 & $\underline{\mathbf{9 5 . 9}}$ \\
\hline Range & \multicolumn{2}{|c|}{$106-189$} \\
Mean \pm SD & \multicolumn{2}{|c|}{$161.57 \pm 15.627$} \\
\hline
\end{tabular}

This table showed that most of the studied nurses $(95.9 \%)$ had satisfactory level of unsatisfactory level of practice with mean \pm practice while the least of them $(4.1 \%)$ had

Table (6): Percent distribution of the studied patients according to the total quality of care level performed by their nurses $(n=145)$.

\begin{tabular}{|l|c|c|}
\hline \multirow{2}{*}{$\begin{array}{c}\text { Total patients' quality of care } \\
\text { level }\end{array}$} & \multicolumn{2}{|c|}{$\begin{array}{c}\text { The studied patients } \\
(\mathbf{n = 1 4 5})\end{array}$} \\
\cline { 2 - 3 } & $\mathrm{N}$ & $\%$ \\
\hline - Low $<60 \%$ & 5 & 3.4 \\
- Moderate $(60-<75) \%$ & $\underline{\mathbf{8 9}}$ & $\underline{\mathbf{6 1 . 4}}$ \\
- High $\geq 75 \%$ & 51 & 35.2 \\
\hline
\end{tabular}

This table illustrated that the majority of the studied sample $(61.4 \%)$ had moderate level of quality of patient care and the minority of the

studied sample (3.4\%) had low level of quality of patient care.

Table (7): Correlation between the competency level of the studied nurses and the quality of patient care level of the studied patients at ICU:

\begin{tabular}{|c|c|c|}
\hline \multirow{2}{*}{ Variables } & \multicolumn{2}{|c|}{ Total } \\
& quality of patient care level \\
\cline { 2 - 3 } & $\mathbf{R}$ & $\mathbf{P}$ \\
\hline Total nurses competency level & $\mathbf{0 . 6 7}$ & $\mathbf{0 . 0 0 0} * *$ \\
\hline
\end{tabular}

This table clarified that there is a highly statistical significant positive correlation between the competency of nurses and the quality of patient care at Intensive Care Units $(\mathrm{r}=0.67, \mathrm{P}=0.000)$. 


\section{Relationship between Nurses' Competencies and Quality of Patient Care at \\ Intensive Care Units}

\section{Discussion:}

Nurses' competency has been proposed as a fundamental element in the provision of nursing care (Khodayarian, Vanaki, Navipour and Vaezi, 2011). Intensive Care nurses should be competent to work under pressure as the Intensive Care environment is a stressful place, especially when dealing with other team members (Schmollgruber, 2015). There is a need for professionals to demonstrate that they are clinically competent to perform certain roles. In this respect, lack of attention to professional competency in nurses can cause problems for organizations and question their activities (Heydari, Kareshki and Armat, 2016). Quality and its measurement are critical and should be integral part of nursing care for continuous improvement and better patient outcomes (Gupta, Shrestha, and Thulung, 2014).

The present study was carried out to investigate the relationship between nurses' competencies and quality of patient care provided in intensive care units at Menoufia University Hospital.

Before discussing the study results related to the study questions, light should be directed toward the socio-demographic characteristics of the study participants who were presented into two groups. In relation to the staff nurses, the results of the present study clarified that the highest percent of nurses in the study sample were at age ranges from 20 to less than 30 years and less than half of the study sample has less than 5 years of experience. In addition, the majority of the study sample nurses were working at intensive care units. Regarding educational level, about three quarters of the study sample nurses had associated degree in nursing. Furthermore, in relation to gender and marital status, approximately two thirds of the studied nurses were female and married. In relation to the patients, this study results showed that the highest percent of the studied patients' age were between 40 to less than 60 years and more than half of them were female. In relation to the length of stay, about two thirds of the studied patients were staying for less than 10 days and the majority of them were present at the intensive care units.

In relation to the level of competencies of intensive care nurses, the present study revealed that more than half of the studied nurses had good level of competence while the lowest percent of them had poor level of competence.

The present study result was congruent with the study of Bahraini, Shahamat, Hayatdavoudi and Mirzaei

(2011) in which the results showed that most of the nurses reported their competence as good. Furthermore, this result was supported by the results of other studies conducted in Iran and other countries of Istomina et al (2011), Hamström, Kankkunen, Suominen and Meretoja (2012), Bahreini, Moattari, Shahamat, Dobaradaran and Ravanipour (2013) and Kajander-Unkuri et., al (2014) and all of them revealed that the nurses' competence level was good. Our study was also in line with Heydari, Kareshki and Armat (2016) who reported that the majority of nurses assessed their overall nursing competencies as good and very good. Besides, another study of Shouryabi, Ghahrisarabi, Anboohi, Nasiri and Rassouli (2017) was consistent with the present study result as it showed that the most of the studied nurses had an excellent level of clinical and professional competence at intensive care units.

On the other hand, two studies of Morolong and Chabeli (2005) and Hengstberger-Sims, Cowin, Eagar, Gregory, Andrew and Rolley (2008) were contradicting to the present study result as the results reported that newly graduated nurses were weak in terms of their clinical competency.

In relation to the nurses' competences domains, the present study results showed that the most of the studied nurses had good knowledge level, positive attitudes and had 


\section{Relationship between Nurses' Competencies and Quality of Patient Care at Intensive \\ Care Units}

satisfactory level of practice. Those domains' levels were considered the main factors that lead to having a good level of competency in this study. So, the formed inter-relations between the main parts or domains of competency and total competency level of the intensive care nurses were explained. Regarding these inter-relations, the present study results showed that there were highly statistical significant positive or negative correlation between the total knowledge level and the total attitude level, the total practice level and the total competency level.

The present study result was supported by the study of Smith (2012), which illustrated that the attributes to nurse competence include integrating knowledge into practice, experience, proficient skills, caring skills and communication skills. Furthermore, the study of Thabet, Ghanem, Ahmed and AbdElMohsen (2019) agreed with the present study result as it illustrated that continued nursing education programs increase both knowledge and practice and can also improve attitudes which enhance the nurses' competencies as a whole.

On the opposite side of our study results, the study of Fulbrook, Albarran, Baktoft and Sidebottom (2012) showed that the basic biological and physiological knowledge did not correlate with selfassessed basic competence.

In relation to the total patient's quality of care level, the present study results' illustrated that the majority of the studied sample had moderate level of quality of patient care and the minority of the studied sample had low level of quality of patient care.

The level of the patient care quality on the present study was measured by assessing the directly presented care to the patients, so it was affected by the nurses' characteristics, nurse to patient ratio and work overload on the department. The present study result was supported by Lui et al (2020) who emphasized that upgrading nurse education level and increasing nurse staffing could potentially improve patient experiences of hospital care and the quality of patient care.

On the other hand, the present study result disagreed with the study of Freitas, Silva, Minamisava, Bezerra and Sousa (2014) who used the same instrument to assess the quality level and whose results presented a low level of nursing care quality despite the presence of a high level of patient satisfaction.

The present study showed that there is a highly statistical significant positive correlation between the competency of nurses and the quality of patient care at Intensive Care Units.

The result of Takase (2012) agreed with the present study result as it showed that the level of nursing competence directly affects the quality of care provided to patients. As well as, Chaboyer, Chamberlain, HewsonConroyetal (2013) clarified that it is important that the relationship between safety culture and basic competence is examined together and attended to in intensive care units and that the nurses' competence is related to quality of nursing care in ICUs and this was in the same line with our study result. Moreover, our study result was supported by the study of Nobahar (2016) which showed that having competence leads to an improved quality of patient care and an increased patient satisfaction with the nurses and helps to promote nursing as a profession and improve nursing education and clinical nursing.

Besides, the present study result is in agreement with the study of Mirlashari, Qommi, Nariman, Bahrani and Begjani, (2016), which illustrated that employing interested and competent nurses and considering the standards required in the Neonatal Intensive Care Units can increase the quality of care in these wards. Also, the study of Nilsson, Gardulf and Lepp (2016) which supported our study result, clarified 
that professional competence in nursing is of crucial importance for high quality care and patient related outcomes. Additionally, the present study result was consistent with Flinkman et., al, (2017) who mentioned that the quality of care was one of the variables that were associated with higher competence.

On the other hand, the findings of Jangland, Nyberg and Yngman-Uhlin (2017) disagreed partially with the present study result as it showed that when nurses, even those with a high level of nursing competence, have to focus on a more critically ill patient while working in the usual patient-nurse ratio, the other patients' needs, including information, nutrition therapy and time for mobilization, are not well met. Besides, the same study of Jangland et., al clarified that when resources were re-allocated and more advanced nursing roles, such as the clinical nurse specialist, were introduced in direct patient care, the leaders found the standard of care to be appropriate.

\section{Conclusion}

The studied sample of nurses had good level of competencies and there was a moderate level of the quality of care for the patients. In relation to the main parts of competency, most of the studied nurses had good level of knowledge, positive attitude and value level and satisfactory level of practice. Finally, this study emphasized that there is a highly statistical significant positive correlation between the competency of nurses and the quality of patient care at Intensive Care Units.

\section{Recommendations}

Based on the findings of the present study, the following recommendations are proposed for practical, educational and research level:

\section{The practical level:}

1. Healthcare organizations should integrate the concepts of nurses' competencies and quality of patient care into the main values and improve them through strategic management.

2. Competence should be assessed regularly in clinical practice to explore individual learning needs for continuing education.

3. Short informed conferences should be performed regularly as a technique of supervision to improve the nurses' competencies in critical care nursing.

4. Training and supervision of health workers are among the most common interventions to improve the quality of health care.

\section{The educational level:}

1. The skill base and biological and physiological knowledge base of intensive and critical care nursing should be strengthened in nursing education with appropriate innovative learning methods, e.g. simulation.

2. Nurses should be encouraged to attend specific meetings as workshops and seminars held for critical care nursing to be acquainted with the most recent advances and skills in the field.

3. Continuing education increase nurses' understanding of intensive care practices, which is vital for improving the quality of patient care.

\section{The research level:}

1. More research is needed to evaluate competencies in different environments, to compare the perceptions of nurses, managers and peers, and to evaluate the nurse competence development.

2. Further research is recommended to compare the level of patient care from different perspectives of managers, nurses, patients and their relatives in those closed units.

\section{References:}




\section{Relationship between Nurses' Competencies and Quality of Patient Care at Intensive \\ Care Units}

Alfieri E., Mori M., Barbui V. and Sarli L., (2017). Advanced competencies mapping of critical care nursing: a qualitative research in two Intensive Care Units Acta Biomed for Health Professions 2017; Vol. 88, S. 3: 67-74 DOI: $10.23750 /$ abm.v88i3-S.6

Ayed A., Sayej S., Harazneh L. et al., (2015). The nurses' knowledge and attitudes towards the palliative care. $\mathbf{J}$ Nurs Edue Pract.; 6(4): 91-9. doi: 10.13140/RG. 2.1.1382.8960.

Bahreini M., Moattari M., Shahamat S., Dobaradaran S. and Ravanipour M., (2013). Improvement of Iranian nurses' competence through professional portfolio: a quasiexperimental study. Nursing \& Health Sciences 2013; 15 (1): 51-7. doi: 10.1111/j.1442-2018. 2012.00733.x

Bahreini M., Shahamat S., Hayatdavoudi P. and Mirzaei M., (2011). Comparison of the clinical competence of nurses working in two university hospitals in Iran. Nurs Health Sci 2011; 13 (3): 282-8. doi: 10. 1111/j. 14422018.2011.00611.x

Berwick D., (2013). A Promise to Learn A Commitment to Act: Improving the Safety of Patients in England. Department of Health, [online]. Available at: https://www.gov.uk/government/publi cations/- [last accessed 7 December 2015].

British Association of Critical Care Nurses (BACCN), (2010). Standards for Nurse Staffing in Critical Care. British Association of Critical Care Nurses, The Critical Care Networks National Nurse Leads, and the Royal College of Nursing Critical Care Forum. Published September 2009, revised January 2010.

Buchan J., O'May F. and Dussault G., (2013). Nursing workforce policy and the economic crisis: a global overview. J Nurs Scholarsh 2013;45:298-307.

Chaboyer W., Chamberlain D. and HewsonConroyetal K., (2013). Safety culture in Australian intensive care units: establishing a baseline for quality improvement. American Journal of Critical Care, vol. 22,no.2,pp.93102,2013.

Chahal H. and Kumari N., (2012). Service quality and performance in the public health-care sector. Health Marketing Quarterly, 29:181-205.

Critical Care Networks National Nurse Leads Group, CC3N, (2012). National Standard for Critical Care Nurse Education. [Online] Available at: http://www.baccn.org.uk/news/12.01. 23.National $\% 20$ Standards $\% 20$ for $\% 20$ Critical\%20Care\%20Nurse\%20Educa tion\%202011.pdf.

European Federation of Critical Care Nursing Association, EfCCNa, (2013). Competencies for European Critical Care Nurses. Available at: http://www.efccna.org/images/stories/ publication/competencies.

Faculty of Intensive Care Medicine (FICM) and the Intensive Care Society (ICS), (2015). Guidelines for the Provision of Intensive Care Services (GPICS), Edition 1, London [online]. Available at: https://www.ficm.ac.uk/newsevents/gpicspublished\%E2\%80\%93guidelinesicm-services-2015 [last accessed 7 December 2015].

Flinkman M., Leino-Kilpi H., Numminen O., Jeon Y., Kuokkanen L. and Meretoja R., (2017). Nurse Competence Scale: a systematic and psychometric review. Journal of Advanced Nursing 73(5), 1035-1050. doi: 10.1111/jan.13183 


\section{Relationship between Nurses' Competencies and Quality of Patient Care at Intensive \\ Care Units}

[14] Francis R., (2013). Report of the Mid Staffordshire NHS Foundation Trust Public Inquiry. The Stationary Office, London [online]. Available at: http://webarchive.

nationalarchives.gov.uk/20150407084 003/http://www.midstaffspublicinquir y. com/report [last accessed 7 December 2015].

Freitas J., Silva A., Minamisava R., Bezerra A. and Sousa M., (2014). "Quality of nursing care and satisfaction of patients attended at a teaching hospital." Rev.Lat.Am.Enfermagem. 22.3 (2014): 454-60.

Fulbrook P., Albarran J., Baktoft B. and Sidebottom B., (2012). A survey of European intensive care nurses' knowledge levels. International Journal of Nursing Studies, vol. 49, no. 2, pp. 191-200, 2012.

Gershengorn H. and Garland A., (2016). Who should be at the bedside 24/7: doctors, families, nurses? Seminars in Respiratory and Critical Care Medicine 37(1), 107-118. doi:10.1055/s-00351570350.

Gerstman B., (2008). Basic biostatistics, Statistics for public health practice. Jones and Bartlet publisher, Inc, 6339 Ormindale Way, Mississauga, Ontario L5V 1J, Canada.

Greenfield D., Kellner A., Townsend K., Wilkinson A. and Lawrence S., (2014). Health service accreditation reinforces a mindset of highperformance human resource management: lessons from an Australian study. International Journal of Quality in Health Care, Vol. 26 No. 4, pp. 372-377.

Gupta B., Shrestha S. and Thulung B., (2014). "Patient's Perception towards Quality Nursing Care." J.Nepal.HealthRes.Counc. $\quad 12.27$ (2014): 83-87.
[Hamström N., Kankkunen P., Suominen T. and Meretoja R., (2012). Short hospital stays and new demands for nurse competencies. International Journal of Nursing Practice 2012; 18: 501-508

Hengstberger-Sims C., Cowin L., Eagar S., Gregory L., Andrew S. and Rolley J., (2008). Relating new graduate nurse competence to frequency of use. Collegian. 2008;15(2):69-76.

Heydari A., Kareshki H. and Armat M., (2016). Is Nurses' Professional Competence Related to Their Personality and Emotional Intelligence? A Cross-Sectional Study. Journal of Caring Sciences 5: 121. $\quad$ https://doi.org/10.15171/jcs .2016.013 PMID: 27354976

Institute of Medicine, (2001). Crossing the quality chasm: a new health system for the 21st century. Washington (DC): National Academies Press; 2001 https://doi. org/10.17226/10027, accessed 25 February 2018).

Istomina N., Suominen T., Razbadauskas A., Martinke'nas A., Meretoja R. and LeinoKilpi H., (2011). Competence of nurses and factors associated with it. Medicina (Kaunas) 47, 230-237.

Jangland E., Nyberg B. and Yngman-Uhlin P., (2017). 'It's a matter of patient safety': understanding challenges in everyday clinical practice for achieving good care on the surgical ward - a qualitative study. Scand J Caring Sci; 2017; 31; 323-331 C 2016 Nordic College of Caring Science

Kajander-Unkuri S., Meretoja R., Katajisto J., Saarikoski M., Salminen L., Suhonen R. and Leino-Kilpi H., (2014). Self-assessed level of competence of graduating nursing students and factors related to it. 


\section{Relationship between Nurses' Competencies and Quality of Patient Care at Intensive Care Units}

Nurse Educ Today 2014; 34 (5): 795 801. doi: 10.1016/j.nedt.2013.08.009

Kendall-Gallagher D. and Blegen M., (2009). Competence and certification of registered nurses and safety of patients in intensive care units. American Journal of Critical Care 18, 106-116.

Khodayarian M., Vanaki Z., Navipour H. and Vaezi AA., (2011). The effect of nursing management development program on clinical competency in coronary care unit. Journal of Kermanshah University of Medical Sciences 15(1):40-50.

Lakanmaa R-L., (2012). Competence in intensive and critical care nursingdevelopment of basic assessment scale for graduating nursing students, Department of Nursing Science, University of Turku, available at: http://www.doria.fi/bitstream/ handle/10024/76824/.

Lakanmaa R-L., Suominen T., Perttila J., Puukka P. and Leino-Kilpi H., (2012). Competence requirements in intensive and critical care nursing - still in need of definition. A Delphi study. Intensive and Critical Care Nursing, vol. 28, no. 6, pp. 329-336,2012.

Lakanmaa R-L., Suominen T., RitmalaCastrén M., Vahlberg T. and LeinoKilpi H., (2015). Basic Competence of Intensive Care Unit Nurses: CrossSectional Survey Study.

Liu X, Zheng J, Liu K, Baggs J., Lui J., Wu Y. and You L., (2020). Associations of nurse education level and nurse staffing with patient experiences of hospital care: A cross sectional study in China. Res Nurs Health. 2020;43:103-113. https://doi.org/10.1002/nur.22003

Meleis A., (2015). Inter-professional Education: A summary of reports and barriers to recommendations. Journal of Nursing Scholarship 48(1), 106-11.

Ministry of Social Affairs and Health, (2009). Promoting Patient Safety Together. Finnish Patient Safety Strategy 2009- 2013. Available at: http://www.stm.fi/c/document library/ get file?folderId=39(accessed 26 September 2011).

Mirlashari J., Qommi R., Nariman S., Bahrani N. and Begjani J., (2016). Clinical Competence and Its Related Factors of Nurses in Neonatal Intensive Care Units. Journal of Caring Sciences, 2016, 5(4), 317-324 doi:10.15171/jcs.2016.033

Moreno R., Singer B. and Rhodes A., (2010). What is an ICU? In: \{Flaatten $\mathrm{H}$, Moreno $\mathrm{R} \mathrm{O}$, Putensen $\mathrm{C}$ \& Rhodes A (eds.)\}. Organisation and Management of Intensive Care. Berlin, 7-13.

Morolong B. and Chabeli M., (2005). Competence of newly qualified registered nurses from a nursing college.

National Competency Framework for Registered Nurses in Adult Critical Care - Critical Care NetworksNational Nurse Leads, CC3N, (2015). Protocol- step 1 competencies version $2-2015$.

Nilsson J., Gardulf A. and Lepp M.,(2016). Process of translation and adaptation of the Nurse Professional Competence (NPC) Scale. Journal of Nursing Education and Practice 2016, Vol. 6, No. 1 EXPERIENCE EXCHANGE

Nobahar M., (2016). Competence of nurses in the intensive cardiac care unit, May 2016,Volume: 8, Issue: 5, Pages: 2395-2404, DOI: http://dx.doi.org/10.19082/2395 
Penoyer D., (2010). Nurse Staffing and patient outcomes in critical care: a concise review. Critical Care Medicine 38, 1521-1528.

Pjjl-Zieber E., Barton S., Konkin J., Owosoga O. and Caine V., (2014). Competence and competency-based nursing education: finding our way through issues. Nurse Education, vol. 34, no.5, pp. 676-678.

Schmollgruber S., (2015).Development of Competency Standards to Inform Intensive Care Nursing Practice, Johannesburg.

Shi L. and Singh D., (2015). Delivering Health Care in America: a Systems Approach. 6th ed. Sudbury, MA: Jones and Bartlett; 2015

Shouryabi A., Ghahrisarabi A., Anboohi S., Nasiri M. and Rassouli M., (2017). Psychometric properties of the Persian version of the Intensive and Critical Care Nursing Competence Scale version-1 (ICCN-CS-1). Electron Physician. $\quad 9(11): 5785-5792$. Published 2017 Nov 25. doi:10.19082/5785

Smith S., (2012). Nurse Competence: A Concept Analysis. NANDA International Journal of Nursing Knowledge Volume 23, No. 3, October 2012

Srisuwan N., Matchim Y. and Nilmanat K., (2014). Nurses' competency in communication with patients at the end of life and their families and related factors. Songklanagarind J Nurs. 34(3): 109-24. Thai.
Takase M., (2012). PROFESSIONAL COMPETANCIES: The relationship between the levels of nurses' competence and the length of their clinical experience: a tentative model for nursing competence development. 15 April 2012, 2012 Blackwell Publishing Ltd, Journal of Clinical Nursing, 22, 1400-1410, doi: 10.1111/j.1365-2702.2012.04239.x

Thabet O., Ghanem H., Ahmed A. and AbdElMouhsen S., (2019). Effect of Developing and Implementing Nursing Care Standards on outcome of Patients Undergoing Cardiac Catheterization. IOSR Journal of Nursing and Health Science (IOSRJNHS), vol. 8, no. 01 , 2019, pp. 4254.

Tongprateep T., (2015). Patent No. 1st national palliative and hospice care conference (NPHC) theme "better health through palliative care" palliative care: For a better life. Ministry of public health in Bangkok;25-26; Nontraburi, Thai.

Welsh Assembly Government, (2009). Post Registration Career Framework for Nurses in Wales. [Online] Available at:

http://www.wales.nhs.uk/sites3/doc uments/580/

Welsh Government, (2013). Together for Health -A Delivery Plan for the Critically Ill. [Online] Available at: http://www.wales.nhs.uk/documents /delivery-plan-for-the-critically-ill. 